\title{
Malignant intraventricular meningioma with craniospinal dissemination and concurrent pulmonary metastasis
}

\author{
Chuan-yuan Tao ${ }^{1}$, Jia-jing Wang ${ }^{2}$, Hao Li ${ }^{1}$ and Chao You ${ }^{1 *}$
}

\begin{abstract}
Background: Malignant intraventricular meningiomas are quite rare and may spread along the craniospinal axis or extraneurally. However, simultaneous cerebrospinal dissemination and distal extraneural metastasis has seldom been reported.

Case presentation: A 51-year-old woman presented with recurrent anaplastic meningioma in the trigone of right lateral ventricle over a 1.5-year period. Suggested radiotherapy was refused after each operation. The patient showed a local relapse and dissemination around the previous tumoral cavity and along the spinal canal during the last recurrence. Left pulmonary metastasis was also found. She died despite multiple lesion resections.

Conclusions: Malignant intraventricular meningiomas are an uncommon subset of intracranial meningiomas, and have a great potential for intraneural and extraneural metastasis. Systemic investigation for metastasis is required after surgery, especially for those without adjuvant therapies.
\end{abstract}

Keywords: CSF dissemination, extraneural metastasis, intraventricular meningioma, malignant

\section{Background}

Meningioma is the second most common intracranial tumor in adults, and usually occurs on the surface of brain with extracranial metastasis reported occasionally [1]. Intraventricular meningioma (IVM) is a rare subset, representing only 0.5 to $3 \%$ of all intracranial meningiomas [2]. Malignant IVM (MIVM) is even rarer. Among MIVMs, single cerebrospinal fluid (CSF) dissemination or distal metastasis has been described separately [3,4]. However, concurrent occurrence has never been reported, to our knowledge. Our case is the first with both craniospinal and extraneural metastasis. We review the pertinent literature and discuss possible metastatic mechanisms. The importance of systemic examinations for early detection of metastasis is also emphasized.

\section{Case presentation}

A 51-year-old woman presented with persistent headache in the right parietooccipital region and blurring of

\footnotetext{
*Correspondence: tcy106@163.com

'Department of Neurosurgery, West China Hospital, Sichuan University, 37

Guoxue Alley, 610041 Chengdu, Sichuan, China

Full list of author information is available at the end of the article
}

vision. Computed tomography $(\mathrm{CT})$ of the head revealed a well-defined, irregular lobulated lesion in the trigone of the right ventricle. The lesion was hyperdense with intratumoral necrosis in its center and slight peritumoral edema (Figure 1A). Further magnetic resonance imaging (MRI) of the brain revealed that the tumor was $7 \times 6 \mathrm{~cm}$ in size and heterogeneous when enhanced by contrast (Figure 1B). The patient underwent a total mass resection under microscopy. The postoperative course was uneventful. Anaplastic meningioma was confirmed by histopathological examination (Figure 1C). The patient refused radiation therapy. No residual tumor was detected three months after surgery (Figure 1D).

One year later, the patient experience a recurrence of headaches and dizziness. Craniospinal MRI displayed a local recurrence (Figure 1E). A second craniotomy was performed to remove the recurrent mass totally, as well as the infiltrated meninges and bone flap. However, suggested radiotherapy was refused once again. She recovered well without any complication and follow-up MRI showed a huge residual cavity without obviously enhanced nodules in the surgical area (Figure 1F). 


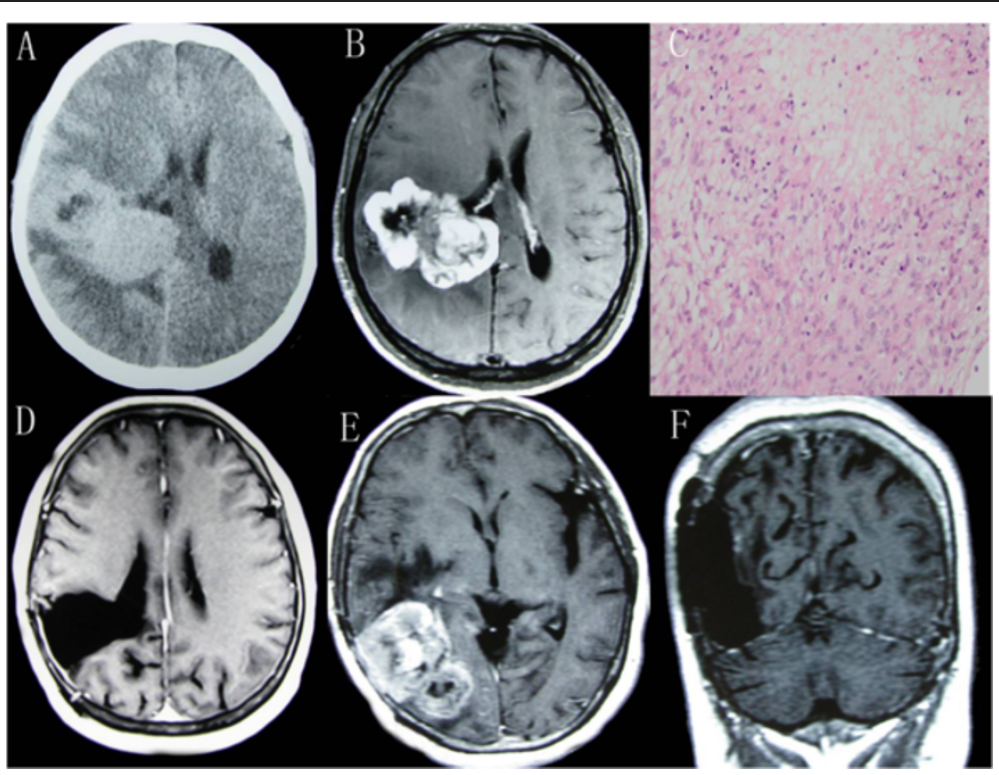

Figure 1 Primary MIVM and first local recurrence. (A) CT scan, showing a huge hyperdense mass lesion in the trigone with central necrosis. (B) MRI scan, demonstrating heterogeneous enhancement of the lesion. (C) Histopathological findings revealing anaplastic meningioma with cellular pleomorphism, nuclear atypia, and geographic necrosis (H \& E 400X). (D) Postoperative MRI scan, displaying no residual tumor. (E) MRI scan, disclosing local recurrence. (F) MRI scan, showing a huge residual cavity after the second craniotomy.

Approximately 18 months after the first operation, regular MRI found a second tumor recurrence and diffuse enhancement around the cavity walls (Figure 2A). Infiltration of the tentorium and transverse sinus was also noted (Figure 2B). Moreover, an enhanced nodule measuring $0.5 \mathrm{~cm}$ in diameter with dural tail was detected in the right temporal region (Figure 2C). Following spinal MRI found a small extramedullary-intradural lesion at the $\mathrm{C} 2$ level and numerous punctate nodules along the spine surface (Figure 2D,E). A systemic search

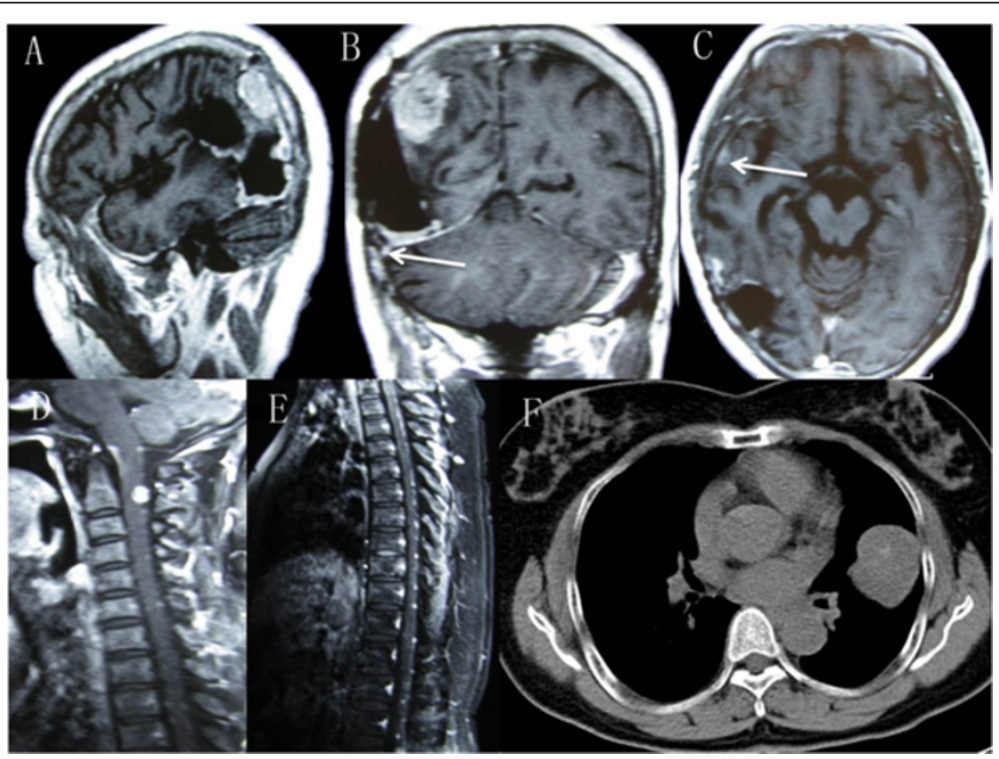

Figure 2 Radiological imaging of intracranial and extracranial metastasis. (A) MRI scan, disclosing local recurrence and diffuse enhancement around the cavity walls. (B) Tumor invasion of the tentorium and transverse sinus was seen (arrow). (C) MRI scan, revealing an enhanced nodule with dural tail in the right temporal lobe. (D, E) Spinal MRI scan with contrast, displaying a small extramedullary-intradural lesion at the C2 level and numerous punctate nodules along the spine surface. (F) Thoracic $C T$ scan, showing a large mass in the left lung. 
for extraneural metastasis including pulmonary and abdominal $\mathrm{CT}$ and bone scanning disclosed a huge mass in the left pulmonary lobe (Figure 2F).

The patient underwent a third craniotomy. During the operation, tumors invading brain parenchyma, the tentorium, and transverse sinus were observed. Resection of the recurrent tumor with adhered brain tissue was carried out, but infiltrated tentorium and transverse sinus were cauterized only. After one week's hospitalization, the patient underwent decompressive excision of cervical mass via $\mathrm{C} 2$ laminectomy because of radicular pain, and anaplastic meningioma was diagnosed. Two weeks later, the left pulmonary mass was resected by thoracotomy, which was consistent with metastatic anaplastic meningioma (Figure 3A-D). The patient died of pneumonia 1 month after the last surgical procedure.

\section{Discussion}

Intraventricular meningiomas are rare tumors, accounting for less than $3 \%$ of all intracranial meningiomas. They originate from the choroid plexus stroma and the tela choroidea absent of dural attachment. The vast majority of IVMs are benign and MIVMs are extremely rare; to the best of our knowledge, only 10 cases have been described so far [3-11]. Nevertheless, eight of these patients experienced subarachnoid dissemination via the CSF [3,5-11]; only one patient had distal metastasis [4].

The clinical data of the 10 MIVMs with CSF dissemination or extracranial metastasis and our case are described in detail (Table 1). There were six females and four males. Ages ranged from 8 to 67 years with 45.5 years on average. Nine lesions were located in the trigone of the lateral ventricle while the other one was found in the third ventricle. Half of the patients were diagnosed with MIVM initially, while the other half had malignancy transformed from benign or atypical meningioma. In seven cases, tumor recurrence was observed, and in four of these there were two recurrences. The mean interval from the initial surgery for primary IVM to the detection of metastasis was 15.7 months (1.5 to 60 months). After surgical resection, eight patients received additional adjuvant therapies, including local or craniospinal irradiation and chemotherapy. However, the outcome was dismal, since the mean survival time was only 15.1 months in the eight documented cases. All the patients died of other systemic complications, mainly pneumonia, except one, who died of bulbar palsy.

Although extracranial metastasis is far more common than CSF dissemination for meningiomas of other locations, whether they are benign or malignant, this is not true for MIVMs [10]. A single report by Garcia-Conde M et al. first depicted a malignant IVM with distal metastasis to the liver [4].

Compared with previous patients, there were two characteristics in the present case that may elucidate its aggressiveness. First, no auxiliary radiotherapy or chemotherapy was applied after operations. Theoretically, free viable cells in the bloodstream or subarachnoid space could reproduce easily to form new metastasis without further radiochemotherapy. Secondly, at the time of

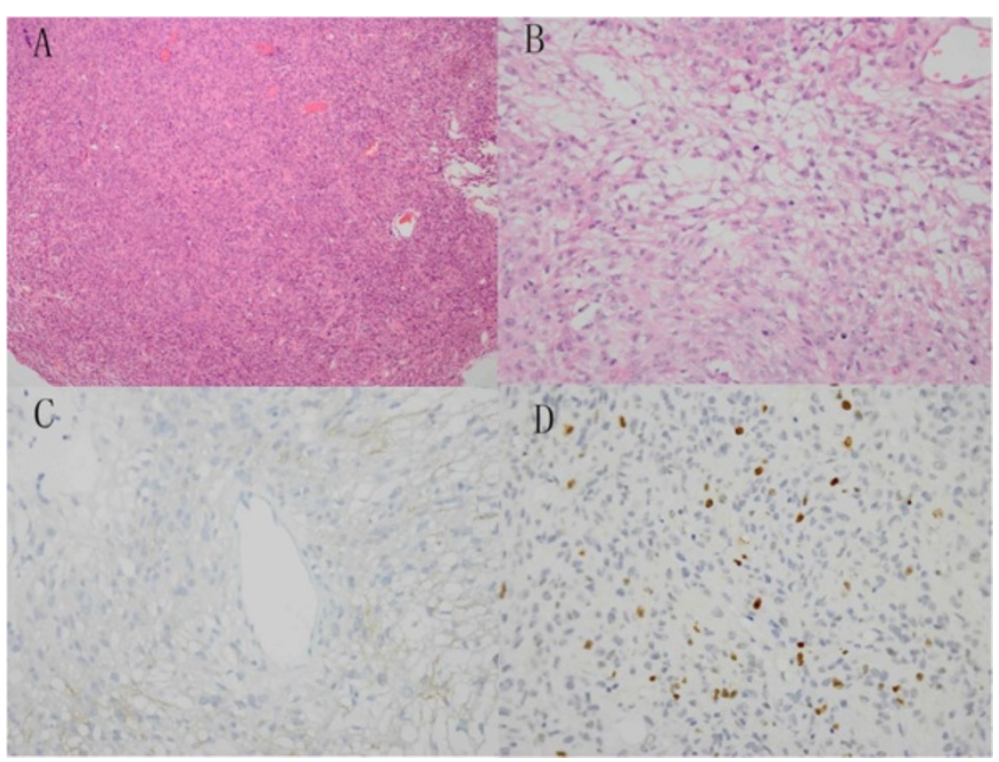

Figure 3 Histopathological examination of lung metastasis. (A) Photomicrograph of lung specimen revealing meningioma cells with increased cellularity (H \& E 40X). (B) Under higher magnification, cellular pleomorphism, nuclear atypia, and necrotic foci were observed (H \& E 400X). (C) Epithelial membrane antigen staining was positive (400x). (D) Moderate Ki-67 proliferation index (>10\%, 400x). 
Table 1 List of MIVMs with cerebrospinal dissemination or extraneural metastasis

\begin{tabular}{|c|c|c|c|c|c|c|c|c|c|}
\hline Reference & Sex, age & Location & $\begin{array}{l}\text { Initial } \\
\text { histology }\end{array}$ & $\begin{array}{l}\text { Time to recur } \\
\text { (months) }\end{array}$ & Metastasis & $\begin{array}{l}\text { Time to metastasis } \\
\text { (months) }\end{array}$ & Auxiliary treatment & $\begin{array}{l}\text { Survival time } \\
\text { (months) }\end{array}$ & Cause of death \\
\hline \multirow[t]{2}{*}{ [5] } & Male, 34 & Trigone & WHO III & 1st recurrence, 12 & Cerebrospinal & 20 & Radiotherapy chemotherapy & 21 & Pneumonia \\
\hline & & & & 2nd recurrence, 7 & & & & & \\
\hline [6] & Female, 61 & Third ventricle & WHO III & none & brain & 1.5 & No & 1.5 & $\begin{array}{l}\text { Sepsis, deep vein } \\
\text { thrombosis }\end{array}$ \\
\hline [7] & Male, 67 & Trigone & WHO III & none & Spinal & 7 & Local irradiation & 12 & Pneumonia \\
\hline [8] & Male, 8 & Trigone & WHO III & 2 & Cerebrospinal & 2 & Radiotherapy, chemotherapy & 6.5 & Not documented \\
\hline \multirow[t]{2}{*}{ [9] } & Female, 34 & Trigone & WHO I & 1st recurrence, 60 & Spinal & 60 & Radiotherapy & $>72$ & Bulbar palsy \\
\hline & & & & 2nd recurrence, 3.5 & & & & & \\
\hline \multirow[t]{2}{*}{ [10] } & Female, 53 & Trigone & WHO ॥ & 1 st recurrence, 4 & Cerebrospinal & 9 & Irradiation & Not documented & Not documented \\
\hline & & & & 2nd recurrence, 4 & & & & & \\
\hline [11] & Female, 61 & Trigone & WHO I & 52 & Cerebrospinal & 2 & $\begin{array}{l}\text { Radiotherapy, gamma-knife } \\
\text { radiation }\end{array}$ & Not documented & Not documented \\
\hline [3] & Female, 42 & Trigone & WHO ॥ & 38 & Spinal & 32 & Radiotherapy & 5 & Pneumonia \\
\hline [4] & Male, 44 & Trigone & WHO ॥ & 2 & Liver & 5 & Radiotherapy & 2 & Hepatic failure \\
\hline \multirow[t]{2}{*}{ Present case } & Female, 51 & Trigone & WHO III & 1st recurrence, 12 & Cerebrospinal, lung & 18 & No & 1 & Pneumonia \\
\hline & & & & 2nd recurrence, 6 & & & & & \\
\hline
\end{tabular}


second recurrence, the tumor was observed to infiltrate the ipsilateral transverse sinus both on preoperative MRI and during the operation. It is postulated that blood-borne passage of tumor cells through dural sinuses is the most likely mechanism for distal metastasis [12].

Many risk factors were suggested to be responsible for the systemic spread, but no definite criteria could be determined, to identify the subgroup of aggressive tumors that will recur or metastasize. Therefore, for MIVM, owing to its susceptibility to spreading via the CSF and the possibility of extraneural metastasis, both neuraxis investigation and assessment of other systemic organs, particularly the lung and liver, should be carefully performed to detect and treat any metastasis as early as possible when tumor relapses.

\section{Conclusions}

Malignant IVMs are extremely rare and may metastasize intracranially, extraneurally alone or simultaneously. Systemic imaging for early metastasis detection must be performed when local recurrence occurs.

\section{Consent}

Written informed consent was obtained from the patient's father for the publication of this report and any accompanying images. A copy of the written consent is available for review by the editor-in-chief of this journal.

\section{Abbreviations}

CSF: cerebrospinal fluid; CT: computed tomography; H \& E: hematoxylin and eosin; IVM: intraventricular meningioma; MIVM: malignant intraventricular meningioma; MRI: magnetic resonance imaging.

\section{Competing interests}

The authors declare that they have no competing interests.

\section{Authors' contributions}

T C-Y carried out the acquisition of the patient's clinical data, and drafted the manuscript. W J-J and L H carried out the collection of pertinent literature. Y C carried out the guidance and revision of the manuscript. All authors read and approved the final manuscript.

\section{Author details}

'Department of Neurosurgery, West China Hospital, Sichuan University, 37 Guoxue Alley, 610041 Chengdu, Sichuan, China. ${ }^{2}$ Department of Neurosurgical ICU, West China Hospital, Sichuan University, 37 Guoxue Alley, 610041 Chengdu, Sichuan, China.

Received: 21 May 2014 Accepted: 20 July 2014

Published: 30 July 2014

\section{References}

1. Scognamiglio G, D'Antonio A, Rossi G, Cavazza A, Camerlingo R, Pirozzi G, La Mantia E, Anniciello AM, Morabito A, Cantile M, Boscaino A, Sparano L, Botti G, Rocco G, Franco R: CD90 expression in atypical meningiomas and meningioma metastasis. Am J Clin Pathol 2014, 141:841-849.

2. Ødegaard KM, Helseth E, Meling TR: Intraventricular meningiomas: a consecutive series of 22 patients and literature review. Neurosurg Rev 2013, 36:57-64.

3. Eom KS, Kim HS, Kim TY, Kim JM: Intraventricular malignant meningioma with CSF-disseminated spinal metastasis: case report and literature review. J Korean Neurosurg Soc 2009, 45:256-259.
4. Garcia-Conde M, Roldan-Delgado H, Martel-Barth-Hansen D, Manzano-Sanz C: Anaplastic transformation of an atypical intraventricular meningioma with metastases to the liver: case report. Neurocirugia (Astur) 2009, 20:541-549.

5. Kleinschmidt-DeMasters BK, Avakian JJ: Wallenberg syndrome caused by CSF metastasis from malignant intraventricular meningioma. Clin Neuropathol 1985, 4:214-219.

6. Strenger SW, Huang YP, Sachdev VP: Malignant meningioma within the third ventricle: a case report. Neurosurgery 1987, 20:465-468.

7. Kamiya K, Inagawa T, Nagasako R: Malignant intraventricular meningioma with spinal metastasis through the cerebrospinal fluid. Surg Neurol 1989, 32:213-218.

8. Greenberg SB, Schneck MJ, Faerber EN, Kanev PM: Malignant meningioma in a child: CT and MR findings. AJR Am J Roentgenol 1993, 160:1111-1112.

9. Peh WC, Fan YW: Case report: intraventricular meningioma with cerebellopontine angle and drop metastases. Br J Radiol 1995, 68:428-430

10. Darwish B, Munro I, Boet R, Renaut P, Abdelaal AS, MacFarlane MR: Intraventricular meningioma with drop metastases and subgaleal metastatic nodule. J Clin Neurosci 2004, 11:787-791.

11. Shintaku M, Hashimoto K, Okamoto S: Intraventricular meningioma with anaplastic transformation and metastasis via the cerebrospinal fluid. Neuropathology 2007, 27:448-452.

12. Erman T, Hanta I, Haciyakupoğlu S, Zorludemir S, Zeren H, Göçer Al: Huge bilateral pulmonary and pleural metastasis from intracranial meningioma: a case report and review of the literature. J Neurooncol 2005, 74:179-181.

doi:10.1186/1477-7819-12-238

Cite this article as: Tao et al:: Malignant intraventricular meningioma with craniospinal dissemination and concurrent pulmonary metastasis. World Journal of Surgical Oncology 2014 12:238.

\section{Submit your next manuscript to BioMed Central and take full advantage of:}

- Convenient online submission

- Thorough peer review

- No space constraints or color figure charges

- Immediate publication on acceptance

- Inclusion in PubMed, CAS, Scopus and Google Scholar

- Research which is freely available for redistribution 